\title{
Cardiovascular Consequences of Acute Kidney Injury
}

\author{
Matthieu Legrand, M.D., Ph.D., and Patrick Rossignol, M.D., Ph.D.
}

From the Department of Anesthesiology and Perioperative Care, University of California, San Francisco, San Francisco (M.L.); and INSERM 942, Lariboisière Hospital, and French Clinical Research Infrastructure Network, Investigation Network Initiative-Cardiovascular and Renal Clinical Trialists (F-CRIN INI-CRCT), Paris (M.L.), and Université de Lorraine, INSERM, Centre d'Investigations Cliniques-Plurithématique 1433, INSERM Unité 1116, Centre Hospitalier Régional Universitaire (CHRU) de Nancy, and F-CRIN INI-CRCT, Nancy (P.R.) - all in France. Address reprint requests to Dr. Legrand at the Department of Anesthesiology and Perioperative Care, University of California, UCSF Medical Center, 500 Parnassus Ave., San Francisco, CA 94143, or at matthieu.legrand@ucsf .edu.

N Engl J Med 2020;382:2238-47. DOI: 10.1056/NEJMra1916393

Copyright @) 2020 Massachusetts Medical Society.
A CUTE KIDNEY INJURY IS GENERALLY CHARACTERIZED BY AN ABRUPT rise in the serum creatinine level, decreased urinary output, or both. ${ }^{1}$ Advances in critical care and renal replacement therapies have provided tools that can support patients through most of the immediate complications of acute kidney injury, such as uremia or hyperkalemia, which could be rapidly fatal. Yet mortality from acute kidney injury remains high. Up to $60 \%$ of patients with severe acute kidney injury who are admitted to an intensive care unit (ICU) die from the disorder ${ }^{2}$; the long-term risk of death associated with acute kidney injury is also increased. ${ }^{3-5}$

Acute kidney injury is associated with an increased risk of chronic and endstage kidney disease ${ }^{6}$ and has adverse effects on other organ systems, including the heart. Likewise, patients with chronic kidney disease are at high risk for acute kidney injury and adverse cardiovascular sequelae..$^{7-9}$ Accumulating evidence supports the notion that cardiovascular damage due to acute kidney injury leads to other poor outcomes ${ }^{10}$ independent of or intertwined with the risks associated with the development of chronic kidney disease (see Fig. S1 in the Supplementary Appendix, available with the full text of this article at NEJM.org). ${ }^{11}$

Interactions between cardiac and kidney diseases have been classified as cardiorenal syndromes. A current classification ${ }^{10}$ includes five types of cardiorenal syndromes: acute cardiac impairment leading to acute kidney injury (type 1), chronic cardiac impairment leading to kidney impairment (type 2), acute kidney injury leading to cardiac impairment (type 3), chronic kidney disease leading to cardiac impairment (type 4), and systemic conditions leading to both cardiac and kidney impairment (type 5) (Fig. S1).

In this review, we discuss the current understanding of the cardiovascular consequences of acute kidney injury (i.e., type 3 cardiorenal syndrome). We also discuss potential preventive strategies that target acute and recovery phases, with the aim of reducing the risk of subsequent adverse clinical events.

\section{EPIDEMIOLOGIC INSIGHTS}

Chronic hypertension and heart failure are risk factors for acute kidney injury and can hamper recovery from kidney injury. ${ }^{12}$ Certain systemic conditions leading to acute kidney injury, such as sepsis, are additional potential causes of cardiovascular damage. ${ }^{7}$

Conversely, acute kidney injury is associated with an increased risk of death and both short-term and long-term cardiovascular complications, such as decompensated heart failure (Fig. 1). The association between acute kidney injury and longterm cardiovascular events has been observed in several large cohort studies (Table S1), although direct comparisons of risk among available studies are of limited 
value, since the definition of acute kidney injury varies from study to study. In 2018, Go et al. reported a study examining the association between acute kidney injury and the risk of cardiovascular events in a large, contemporary, matched U.S. cohort of 430,159 hospitalized adults (39,153 of whom had acute kidney injury)..$^{13}$ During the patients' first year after discharge, the risk of hospitalization for heart failure was increased by $44 \%$ in the group with acute kidney injury as compared with the group that did not have kidney injury. In a Canadian populationbased study involving 156,690 patients who survived a hospitalization complicated by acute kidney injury, 1 in 5 patients was readmitted within 30 days, most often with heart failure. ${ }^{14}$

A 2017 meta-analysis of 25 studies involving a total of 254,408 patients, including 55,150 with acute kidney injury, ${ }^{15}$ showed that the condition was associated with an $86 \%$ increase in the risk of death from cardiovascular causes $(95 \%$ confidence interval [CI], 72 to 101) during a median follow-up of 1.4 years (interquartile range [IQR], 1.3 to 1.9$)$. There was a $58 \%$ increase $(95 \% \mathrm{CI}$, 46 to 72 ) in the risk of chronic heart failure during 2.9 years of follow-up (IQR, 1.7 to 3.8), a $40 \%$ increase ( $95 \%$ CI, 23 to 59 ) in the risk of acute myocardial infarction during 2.3 years of follow-up (IQR, 0.7 to 2.9), and a 15\% increase (95\% CI, 3 to 28 ) in the risk of stroke over a period of 2.7 years (IQR, 2.0 to 3.4). ${ }^{15}$ The increased relative risk did not differ between patients with and those without chronic kidney disease, and neither status with respect to recovery of renal function nor severity of acute kidney injury was associated with a change in the risk of myocardial infarction. Such associations suggest that the long-term risk of cardiovascular

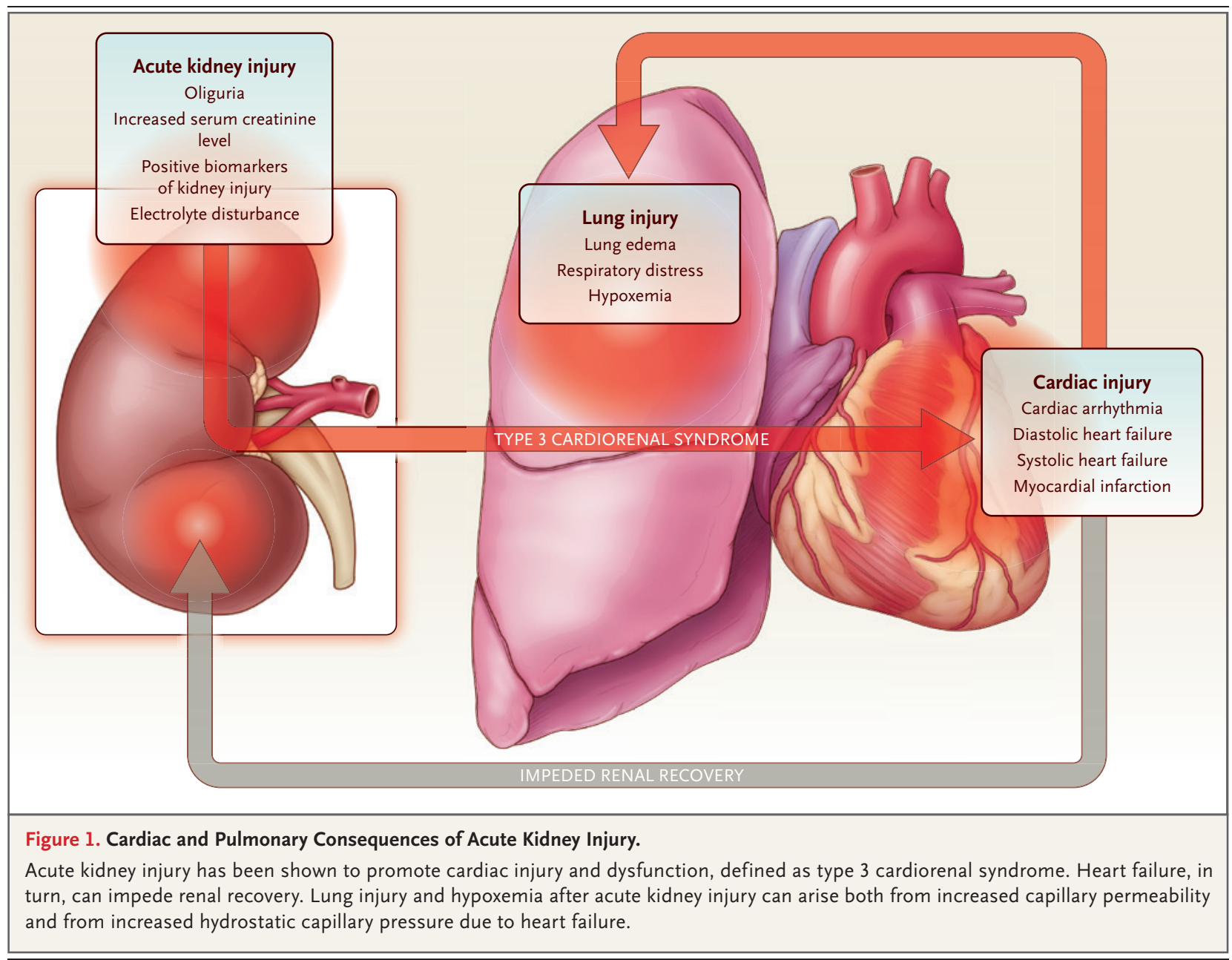


events is associated with the acute kidney injury itself and not only with the risk of end-stage kidney disease. ${ }^{16-18}$

Moreover, a history of heart failure is not the sole driver of the risk of cardiovascular events. Bansal et al. ${ }^{19}$ reported that among patients without a history of heart failure, the occurrence of acute kidney injury was associated with a $23 \%$ increase in the risk of incident heart failure (hazard ratio, 1.23; 95\% CI, 1.19 to 1.27). In a sensitivity analysis that excluded patients with cardiovascular risk factors, the risk associated with acute kidney injury was 38\% (hazard ratio, 1.38; $95 \%$ CI, 1.21 to 1.56 ). ${ }^{19}$ The long-term burden of acute kidney injury has also been shown in a U.S. cohort of 210,895 adults without a history of heart failure. ${ }^{20}$ Patients with communityacquired acute kidney injury had approximately twice the risk of hospitalization for new heart failure within 365 days as did patients without acute kidney injury, in an analysis controlled for baseline and clinical characteristics. In a study involving children and young adults admitted to an ICU, those with acute kidney injury in the absence of other coexisting conditions had an increased risk of death. ${ }^{21}$ Finally, analyses of claims databases show that patients with acute kidney injury are more likely than patients without such injury to have subsequent hypertension (46.1\% vs. $41.2 \%, \mathrm{P}<0.001){ }^{22}$ Hypertension thus appears likely to be associated with the poor cardiovascular and renal outcomes of acute kidney injury.

\section{PATHOPHYSIOLOGY}

Although the pathophysiology of cardiovascular damage after acute kidney injury is not fully understood, several factors appear to be involved (Figs. 2 and 3). The most prominent are cardiac inflammation, cardiac fibrosis, neurohormonal activation, and electrolyte disturbances. ${ }^{23,24}$

In some animal models, a transient episode of ischemic acute kidney injury increases plasma levels of certain circulating inflammatory mediators (e.g., tumor necrosis factor $\alpha$ [TNF- $\alpha$ ], interleukin-1, interleukin-6, intercellular adhesion molecule 1 , and interferon- $\gamma$ ). ${ }^{25}$ Some of these cytokines exert direct cardiodepressant effects. ${ }^{26}$ Renal ischemia induces apoptosis of cardiac muscle cells, as well as inflammation, including leukocyte infiltration, within 48 hours after re- perfusion, ${ }^{27,28}$ and blocking TNF- $\alpha$ limits the apoptosis. ${ }^{27}$ In mice, acute kidney injury induces cardiac mitochondrial injury, which is associated with apoptosis and diastolic dysfunction within 72 hours and can be prevented by inhibition of dynamin-related protein 1 , a protein central to mitochondrial fusion and fragmentation. ${ }^{29} \mathrm{Ex}-$ perimentally induced ischemic acute kidney injury in rats affects the metabolomic profile in the heart, with altered metabolism, amino acid depletion, increased oxidative stress, and a shift toward anaerobic forms of energy production, as well as echocardiographic signs of diastolic dysfunction, ${ }^{30,31}$ all findings that are similar to those observed after direct ischemic myocardial injury. In mice, kidney failure induced by subtotal nephrectomy increases cardiac susceptibility to ischemic-reperfusion injury and an associated down-regulation of cardiac adiponectin signaling. ${ }^{32}$ It is difficult to generalize such preclinical insights to acute kidney injury in humans, owing to limitations and pitfalls of animal models of inflammation, such as sex- and strain-related differences in the immune responses of rodents, variable expression of some molecular markers, or the presence of factors that limit the systemic proinflammatory response. ${ }^{33}$

Biomarker studies in patients provide additional relevant translational insights. Several biomarkers that are up-regulated after acute kidney injury in humans have been found to be associated with an increased number of cardiovascular events, and the underlying pathways of these biomarkers may play a role in the development of cardiovascular damage. For example, neutrophil gelatinase-associated lipocalin (NGAL), a protein expressed in renal tubular epithelial cells $^{34}$ and in immune cells, was reported to be associated with the development of cardiac fibrosis after mineralocorticoid-receptor activation. ${ }^{35-37}$ Recently, in a nested, matched, case-control study involving patients with incident heart failure, 89 of 252 circulating plasma proteins in the discovery set and 38 in the replication set were associated with heart failure. ${ }^{38}$ Furthermore, for these validated proteins, four major pathways were involved: inflammation and apoptosis; growth, angiogenesis, and extracellular-matrix remodeling; metabolism; and the renin-angiotensin-aldosterone system. ${ }^{34-38}$ Two of the identified proteins, insulin-like growth factor-binding protein 7 (IGF-BP7), a biomarker of cell-cycle 


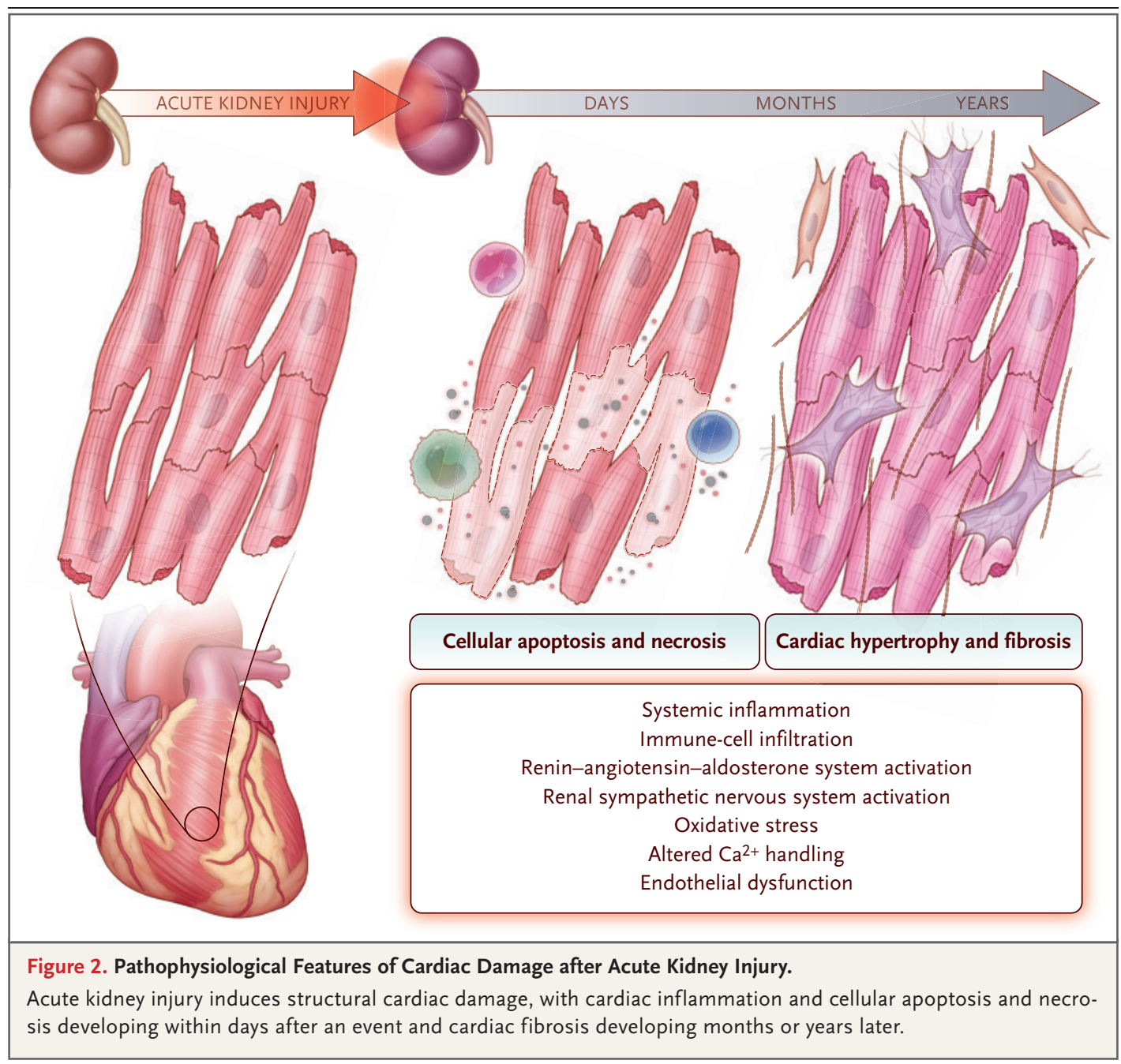

arrest, and kidney injury molecule 1 (KIM-1), are also increased during kidney injury. With the use of a complex-network approach, several biomarkers have been shown to be linked by known protein interactions, biochemical interactions, or gene regulatory pathways (including a cluster depicting inflammation or apoptosis and the renin-angiotensin-aldosterone system) involved in acute kidney injury (Fig. S2). ${ }^{34-38}$ Such observations further support the concept of incident heart failure triggered by acute kidney injury.

Induction of the renin-angiotensin-aldosterone system is a hallmark of the cardiovascular response to acute kidney injury and appears to trigger a cardiac immune response and subsequent fibrosis. ${ }^{39-41}$ Angiotensin II has long been recognized as a factor that mediates cardiac hypertrophy and impaired cardiac function and induces macrophage infiltration, cardiac inflammation, and myocardial fibrosis.

Activation of the renal sympathetic nervous system also contributes to cardiac injury after acute kidney injury, furthering the likelihood of endothelial dysfunction and cardiac fibrosis, as well as ventricular dysfunction. ${ }^{42}$ Polhemus et al. ${ }^{43}$ showed that blockage of the renal sympathetic nervous system prevented cardiac damage, in part through inhibition of angiotensin II and renal neprilysin activity. The protective effects of renal sympathetic denervation were partially reproduced by the use of bisoprolol, a $\beta_{1}$ antagonist. ${ }^{43}$ The parenchymal scarring mediated by the fibrogenic response to acute kidney injury may ultimately lead to heart failure. ${ }^{44}$

The cardiac consequences of acute kidney injury might also be mediated by the lectin pro- 


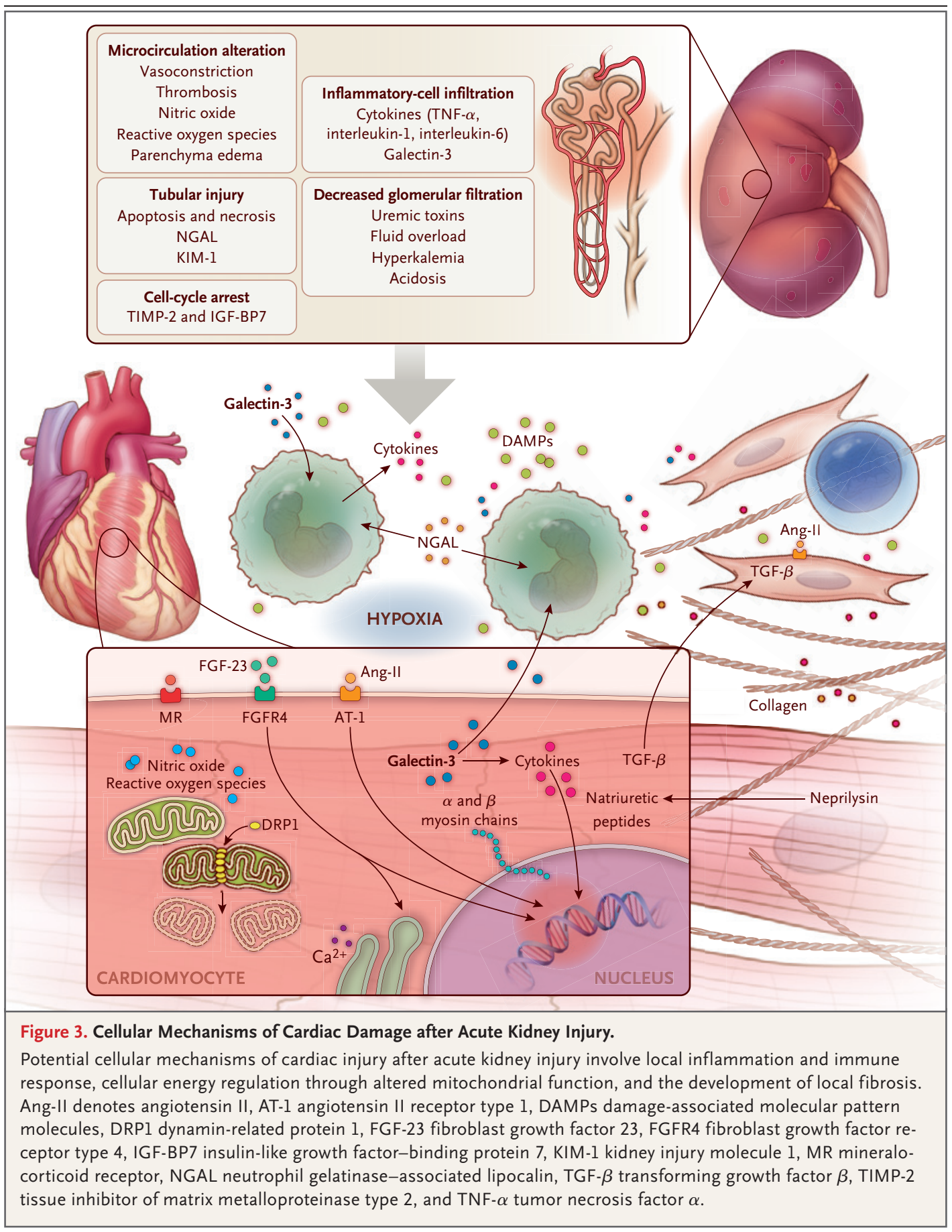

tein galectin-3,45-47 as shown in studies of mice with acute kidney injury in which galectin-3 induced cardiac inflammation, cardiac fibrosis, ${ }^{48}$ and cardiac failure. Furthermore, increased expression of galectin-3 has been associated with cardiac damage after acute kidney injury in critically ill patients (Fig. S3). ${ }^{49}$ In a community- based cohort study, alteration of kidney function has been reported to be associated with increased galectin-3 levels, whereas the degree of longitudinal rise in galectin-3 levels predicts future heart failure..$^{50}$

In other studies, fibroblast growth factor 23 (FGF-23), a predominantly bone-derived hormone 


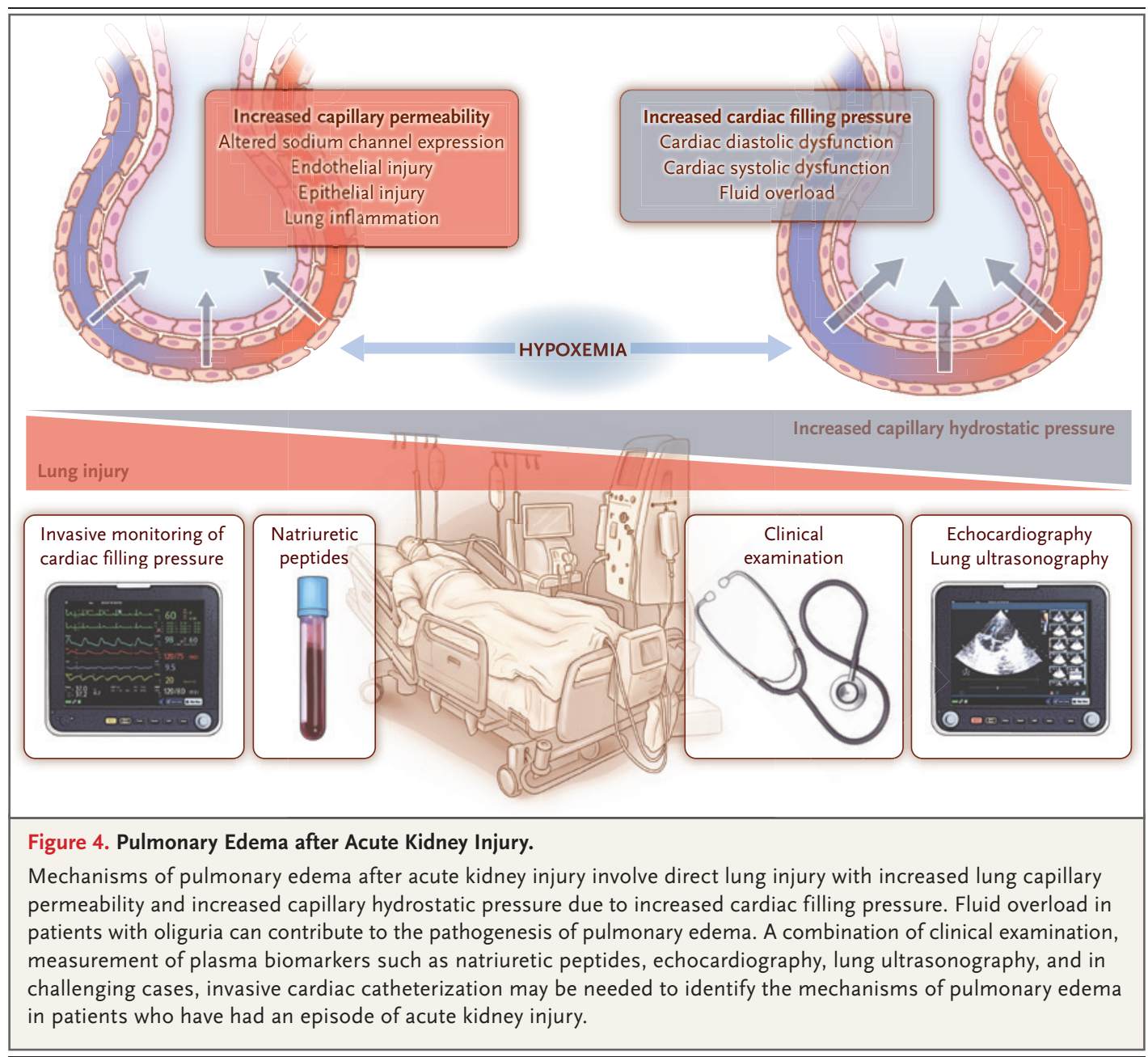

involved in phosphate homeostasis, has been described as a likely mediator of cardiovascular disease associated with chronic kidney disease. FGF-23 was observed to be rapidly up-regulated after an episode of acute kidney injury in a murine model. ${ }^{51}$ In addition, reduced expression of klotho, a coreceptor of FGF-23, has been linked to secondary cardiac damage after acute kidney injury (as reviewed by Christov et al.). ${ }^{52}$

Electrolyte disturbances and metabolic acidosis are also thought to contribute to cardiac manifestations after acute kidney injury. Hyperkalemia can induce electrophysiological disturbances that alter cardiac conduction and potentially lead to cardiac arrest. ${ }^{53}$ In rats, acute kidney injury increases the risk of ventricular arrhythmia after myocardial infarction because of distorted intracellular calcium homeostasis due to changes in the dihydropyridine receptor on the L-type calcium channel. ${ }^{31}$ Profound metabolic acidosis alters myocyte contraction and excitability in vitro. $^{54}$

\section{DIAGNOSTIC FEATURES}

Patients with, or recovering from, acute kidney injury often present with clinical signs and symptoms of heart failure, but the diagnosis can be challenging in such patients, since the symptoms are often nonspecific. Biomarkers and imaging techniques are frequently used for diagnostic purposes and to guide treatment decisions and monitor the response to therapy (Fig. 4). Capillary pulmonary pressure measured with a pulmonary-artery catheter can provide useful information regarding possible lung injury or cardiogenic pulmonary edema. Echocardiography, which has become the standard of care for 
evaluating cardiac function and left ventricular filling pressures, can be used to detect an altered ejection fraction and cardiac diastolic dysfunction.

Brain natriuretic peptide (BNP) and, more often, $\mathrm{N}$-terminal pro-B-type natriuretic peptide (NT-proBNP), are commonly used as biomarkers of heart failure. ${ }^{55,56}$ However, there is no consensus on cutoff values to define heart failure in patients with acute kidney injury, and both false positive and false negative results indicating high cardiac filling pressures have been reported. ${ }^{55}$ In patients with kidney disease independent of heart failure, elevated plasma levels of these peptides are often found as a result of reduced renal clearance. The renal clearance of natriuretic peptides ranges from 15 to $60 \% .^{56,57}$ The effect of a reduced glomerular filtration rate on plasma levels of natriuretic peptides, however, appears to be greatest in patients with severely impaired renal function or in patients receiving dialysis. ${ }^{58}$ Therefore, elevated natriuretic peptide levels (both absolute values and variation in plasma levels over time) most likely reflect a contribution of increased cardiac filling pressure in patients with mild altered renal function rather than a decrease in glomerular filtration. ${ }^{58}$ Levels of cardiac troponin, a biomarker for myocardial injury, are frequently elevated in patients with renal dysfunction - specifically, in 30 to $75 \%$ of patients receiving hemodialysis. ${ }^{59}$ Since plasma troponin levels can be affected by both cardiac injury and decreased renal clearance, a single measurement may be insufficient to diagnose acute cardiac ischemia. In our view, the clinical presentation, electrocardiographic findings, and kinetics of troponin are all important to consider in the diagnosis of an acute coronary syndrome in patients with acute kidney injury.

DIAGNOSTIC AND THERAPEUTIC APPROACHES TO CARDIORENAL OUTCOMES

An early and rapid diagnostic test to detect acute kidney injury is important to maximize the effect of mitigating strategies that are likely to improve cardiorenal outcomes. Despite the established clinical importance of acute kidney injury, it has eluded diagnosis in up to $25 \%$ of cases in developed countries and in up to $75 \%$ of cases in developing countries, ${ }^{15,60}$ with a correspondingly high burden of cardiovascular sequelae. Although prevention of the occurrence or progression of acute kidney injury is a critical goal, many cases are diagnosed only in the late stages. Earlier identification with the use of artificial intelligence algorithms ${ }^{61}$ or measurement of sensitive biomarkers, such as combined measurement of the tissue inhibitor of matrix metalloproteinase 2 and IGF-BP7 or measurement of NGAL or proenkephalin, has been reported to facilitate the detection of acute kidney injury. ${ }^{62,63}$ Early recognition of acute kidney injury could improve the chances of a successful outcome through early implementation of care strategies (e.g., facilitation of focused evaluation, avoidance of nephrotoxins, and hemodynamic optimization). ${ }^{64}$ Biomarker levels that suggest acute kidney injury in survivors of ICU stays have been reported to be associated with an increased 1-year risk of death ${ }^{65}$; thus, it has been suggested that the use of biomarkers to identify patients likely to benefit from renal preventive strategies would be important. ${ }^{64}$ To this end, obtaining a nephrology or intensive care consultation has been suggested for patients with a diagnosis of acute kidney injury. ${ }^{66}$

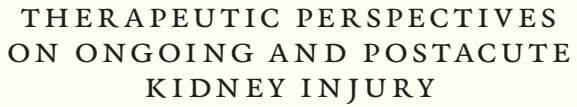

Fluid overload is common in patients with acute kidney injury and is associated with poor outcomes. ${ }^{67}$ Both reduced cardiac function and fluid overload can contribute to increased pulmonary capillary hydrostatic pressure. The risk of pulmonary edema after acute kidney injury can be further enhanced by increased pulmonary capillary permeability (Fig. 4) ${ }^{68}$ which may be mediated by pulmonary inflammation, endothelial injury, altered sodium-channel expression, or oxidative stress. ${ }^{69}$ Acute kidney injury can be associated with hypoxemia, which leads to increased and prolonged use of mechanical ventilation in patients admitted to the ICU..$^{70}$ Diuretics or ultrafiltration techniques have been shown to be helpful in controlling fluid balance in patients who have acute kidney injury with fluid overload. ${ }^{71}$ Such approaches should ideally be guided by measurement or estimation of vascular and cardiac filling pressures with the use of the diagnostic methods described above. Invasive moni- 
toring of central venous or right atrial pressure can also be used to guide treatment in the most severely affected patients. However, improved monitoring strategies during treatment of acute kidney injury remain to be prospectively assessed in trials with definitive renal and cardiovascular end points.

Recognized indications for renal replacement therapy are complications of severe acute kidney injury, such as severe fluid overload that is not controlled with diuretics or severe hyperkalemia. But early use of renal replacement therapy has failed to improve outcomes among critically ill patients with acute kidney injury, ${ }^{72,73}$ and only a minority of such patients receive renal replacement therapy ( $5 \%$ in a population-based study of residents in Canada). ${ }^{74}$ Hemodialysis-induced circulatory stress and reduced renal perfusion have been shown to be associated with repeated episodes of myocardial ischemia and stunning. ${ }^{75}$ For patients receiving renal replacement therapy, the use of higher dialysate sodium levels, lower temperature, and individualized ultrafiltration rates have been proposed to improve hemodynamic tolerance of hemodialysis, but with minimal evidence to date. ${ }^{76,77}$

The use of renin-angiotensin-aldosterone system inhibitors is associated with improved outcomes in patients recovering from acute kidney injury ${ }^{78}$ and strategies to prevent cardiovascular damage by reducing activation of the renin-angiotensin-aldosterone system are likely to improve long-term outcomes. In an observational study of the association between renin-angiotensinaldosterone system inhibition and mortality among 1551 critically ill patients, prescription of an angiotensin-converting-enzyme (ACE) inhibitor or angiotensin-receptor blocker (ARB) at the time of discharge was associated with a reduced risk of all-cause mortality at 1 year (hazard ratio, 0.47 ; $95 \%$ CI, 0.27 to 0.82 ), after adjustment for other prognostic factors. ${ }^{78}$ Similar findings were observed in a cohort study involving 46,253 patients who had an episode of acute kidney injury during hospitalization: use of a renin-angiotensin system inhibitor after discharge was associated with improved survival (hazard ratio for death, 0.85; $95 \%$ CI, 0.81 to 0.89 ), although there was an increased risk of hospitalization for renal causes among treated patients. ${ }^{79}$ Since this was an observational study, confounding by indication is a possibility. Temporary discontinuation of ACE inhibitors and ARBs has been advocated for patients undergoing surgery. ${ }^{64}$ Yet it remains largely unknown whether withholding or continuing these treatments before major surgery influences the outcome, and the effects are currently being investigated. ${ }^{80}$

Follow-up by a nephrologist after an episode of acute kidney injury has been associated with reduced all-cause mortality (hazard ratio, 0.76; $95 \%$ CI, 0.62 to 0.93$).{ }^{81}$ Strikingly, however, only a minority of at-risk survivors of acute kidney injury are referred to a nephrologist for ongoing care. ${ }^{82}$ The relatively small number of nephrologists has been proposed as a reason for the low rate of referral. Enlisting primary care providers to screen patients for persistent renal dysfunction and subclinical cardiovascular and renal damage, with selective referral to a nephrologist, cardiologist, or both, may be a more pragmatic approach. This may allow the simultaneous management of cardiac and renal triggers and the consequences of chronic cardiorenal syndrome. Such an approach would include the management or prevention of associated cardiovascular risk factors (e.g., treatment of hypertension and management of obesity or dyslipidemia), interventions to address malnutrition or electrolyte disturbances, avoidance of nephrotoxicity, and individualized adjustment of medications shown to improve clinical outcomes across the cardiovascular and renal continuum in patients with stable chronic kidney disease (e.g., reninangiotensin-aldosterone system inhibitors and sodium-glucose cotransporter 2 inhibitors) (Table S2). ${ }^{44}$

\section{SUM MARY}

Acute kidney injury is recognized as a potential risk factor for future cardiovascular events, especially heart failure. Preclinical models and biomarkers have identified several likely pathophysiological mechanisms, apparently involving mitochondrial injury, inflammation, cellular death, and profibrotic pathways. The therapeutic use of blockers of the renin-angiotensin-aldosterone system may be associated with improved outcomes in patients recovering from acute kidney injury, but interventional trials are needed to refine strategies for treating patients after an acute episode. We believe that it is important for health care professionals to be aware of acute 
kidney injury and its effect on the cardiovascular system, if patients are to receive needed, potentially lifesaving treatments.
Disclosure forms provided by the authors are available with the full text of this article at NEJM.org.

We thank Dr. Pelle Stolt for assistance with an earlier draft of the manuscript.
REFERENCES

1. Kidney Disease: Improving Global Outcomes (KDIGO) Acute Kidney Injury Work Group. KDIGO clinical practice guideline for acute kidney injury. Kidney Int Suppl 2012;2:6.

2. Hoste EAJ, Bagshaw SM, Bellomo R, et al. Epidemiology of acute kidney injury in critically ill patients: the multinational AKI-EPI study. Intensive Care Med 2015; 41:1411-23.

3. Sawhney S, Marks A, Fluck N, Levin A, Prescott G, Black C. Intermediate and long-term outcomes of survivors of acute kidney injury episodes: a large populationbased cohort study. Am J Kidney Dis 2017; 69:18-28.

4. Horkan CM, Purtle SW, Mendu ML, Moromizato T, Gibbons FK, Christopher $\mathrm{KB}$. The association of acute kidney injury in the critically ill and postdischarge outcomes: a cohort study. Crit Care Med 2015; 43:354-64.

5. Coca SG, Yusuf B, Shlipak MG, Garg AX, Parikh CR. Long-term risk of mortality and other adverse outcomes after acute kidney injury: a systematic review and meta-analysis. Am J Kidney Dis 2009;53: 961-73.

6. Coca SG, Singanamala S, Parikh CR. Chronic kidney disease after acute kidney injury: a systematic review and metaanalysis. Kidney Int 2012;81:442-8.

7. Martin L, Derwall M, Al Zoubi S, et al. The septic heart: current understanding of molecular mechanisms and clinical implications. Chest 2019;155:427-37.

8. Gansevoort RT, Correa-Rotter R, Hemmelgarn BR, et al. Chronic kidney disease and cardiovascular risk: epidemiology, mechanisms, and prevention. Lancet 2013; 382:339-52.

9. Turin TC, Tonelli M, Manns BJ, Ravani P, Ahmed SB, Hemmelgarn BR. Chronic kidney disease and life expectancy. Nephrol Dial Transplant 2012;27:3182-6. 10. Ronco C, Bellasi A, Di Lullo L. Cardiorenal syndrome: an overview. Adv Chronic Kidney Dis 2018;25:382-90.

11. Bansal N, Zelnick L, Bhat Z, et al. Burden and outcomes of heart failure hospitalizations in adults with chronic kidney disease. J Am Coll Cardiol 2019;73:2691700 .

12. Legrand M, Dupuis C, Simon C, et al. Association between systemic hemodynamics and septic acute kidney injury in critically ill patients: a retrospective observational study. Crit Care 2013;17:R278. 13. Go AS, Hsu C-Y, Yang J, et al. Acute kidney injury and risk of heart failure and atherosclerotic events. Clin J Am Soc Nephrol 2018;13:833-41.
14. Silver SA, Harel Z, McArthur E, et al. 30-Day readmissions after an acute kidney injury hospitalization. Am J Med 2017 130(2):163.e4-172.e4.

15. Odutayo A, Wong CX, Farkouh M, et al $\mathrm{AKI}$ and long-term risk for cardiovascula events and mortality. J Am Soc Nephro 2017;28:377-87.

16. Gallagher M, Cass A, Bellomo R, et al Long-term survival and dialysis dependency following acute kidney injury in intensive care: extended follow-up of a randomized controlled trial. PLoS Med 2014;11(2):e1001601.

17. Linder A, Fjell C, Levin A, Walley KR, Russell JA, Boyd JH. Small acute increases in serum creatinine are associated with decreased long-term survival in the critically ill. Am J Respir Crit Care Med 2014; 189:1075-81.

18. Hsu C, Chertow GM, McCulloch CE Fan D, Ordoñez JD, Go AS. Nonrecovery of kidney function and death after acute on chronic renal failure. Clin J Am Soc Nephrol 2009;4:891-8.

19. Bansal N, Matheny ME, Greevy RA Jr, et al. Acute kidney injury and risk of incident heart failure among US veterans. Am J Kidney Dis 2018;71:236-45.

20. Tecson KM, Hashemi H, Afzal A, Gong TA, Kale P, McCullough PA. Communityacquired acute kidney injury as a risk factor of de novo heart failure hospitalization. Cardiorenal Med 2019;9:252 60.

21. Kaddourah A, Basu RK, Bagshaw SM Goldstein SL. Epidemiology of acute kidney injury in critically ill children and young adults. N Engl J Med 2017;376:11-20.

22. Hsu C, Hsu RK, Yang J, Ordonez JD, Zheng S, Go AS. Elevated BP after AKI. J Am Soc Nephrol 2016;27:914-23.

23. Bagshaw SM, Hoste EA, Braam B, et al. Cardiorenal syndrome type 3: pathophysiologic and epidemiologic considerations Contrib Nephrol 2013;182:137-57.

24. Martin-Lorenzo M, Gonzalez-Calero L, Ramos-Barron A, et al. Urine metabolomics insight into acute kidney injury point to oxidative stress disruptions in energy generation and $\mathrm{H}_{2} \mathrm{~S}$ availability. J Mol Med (Berl) 2017;95:1399-409. 25. Dépret F, Prud'homme M, Legrand M A role of remote organs effect in acute kidney injury outcome. Nephron 2017;137: 273-6.

26. Bartekova M, Radosinska J, Jelemensky M, Dhalla NS. Role of cytokines and inflammation in heart function during health and disease. Heart Fail Rev 2018; 23:733-58.

27. Kelly KJ. Distant effects of experimen- tal renal ischemia/reperfusion injury. J Am Soc Nephrol 2003;14:1549-58.

28. Kompotiatis P, Wiley BM, Jentzer JC, Kashani KB. Echocardiographic parameters of patients in the intensive care unit undergoing continuous renal replacement therapy. PLoS One 2019;14(1):e0209994. 29. Sumida M, Doi K, Ogasawara E, et al. Regulation of mitochondrial dynamics by dynamin-related protein- 1 in acute cardiorenal syndrome. J Am Soc Nephrol 2015; 26:2378-87.

30. Fox BM, Gil H-W, Kirkbride-Romeo L, et al. Metabolomics assessment reveals oxidative stress and altered energy production in the heart after ischemic acute kidney injury in mice. Kidney Int 2019;95: 590-610.

31. Robinson SC, Bowmer CJ, Yates MS. Cardiac function in rats with acute renal failure. J Pharm Pharmacol 1992;44:100714.

32. Song Y, Yu Q, Zhang J, et al. Increased myocardial ischemia-reperfusion injury in renal failure involves cardiac adiponectin signal deficiency. Am J Physiol Endocrinol Metab 2014;306:E1055-E1064.

33. Rabb H, Griffin MD, McKay DB, et al. Inflammation in AKI: current understanding, key questions, and knowledge gaps. J Am Soc Nephrol 2016;27:371-9.

34. $\mathrm{Xu} \mathrm{K}$, Rosenstiel $\mathrm{P}$, Paragas $\mathrm{N}$, et al. Unique transcriptional programs identify subtypes of AKI. J Am Soc Nephrol 2017; 28:1729-40.

35. Tarjus A, Martínez-Martínez E, Amador C, et al. Neutrophil gelatinase-associated lipocalin, a novel mineralocorticoid biotarget, mediates vascular profibrotic effects of mineralocorticoids. Hypertension 2015;66:158-66.

36. Martínez-Martínez E, Buonafine $M$, Boukhalfa I, et al. Aldosterone target NGAL (neutrophil gelatinase-associated lipocalin) is involved in cardiac remodeling after myocardial infarction through $\mathrm{NF} \kappa \mathrm{B}$ pathway. Hypertension 2017;70:1148-56. 37. Buonafine M, Martínez-Martínez E, Amador C, et al. Neutrophil gelatinaseassociated lipocalin from immune cells is mandatory for aldosterone-induced cardiac remodeling and inflammation. J Mol Cell Cardiol 2018;115:32-8.

38. Ferreira JP, Verdonschot J, Collier T, et al. Proteomic bioprofiles and mechanistic pathways of progression to heart failure. Circ Heart Fail 2019;12(5):e005897.

39. Crowley SD, Rudemiller NP. Immunologic effects of the renin-angiotensin system. J Am Soc Nephrol 2017;28:1350-61. 40. Alge JL, Karakala N, Neely BA, et al. Association of elevated urinary concen- 
tration of renin-angiotensin system components and severe AKI. Clin J Am Soc Nephrol 2013;8:2043-52.

41. Alge JL, Karakala N, Neely BA, Janech MG, Velez JCQ, Arthur JM. Urinary angiotensinogen predicts adverse outcomes among acute kidney injury patients in the intensive care unit. Crit Care 2013;17:R69 42. Sharp TE III, Polhemus DJ, Li Z, et al. Renal denervation prevents heart failure progression via inhibition of the reninangiotensin system. J Am Coll Cardiol 2018;72:2609-21.

43. Polhemus DJ, Trivedi RK, Gao J, et al. Renal sympathetic denervation protects the failing heart via inhibition of neprily sin activity in the kidney. J Am Coll Cardiol 2017;70:2139-53.

44. Zannad F, Rossignol P. Cardiorenal syndrome revisited. Circulation 2018;138: 929-44.

45. Calvier L, Martinez-Martinez E, Mian $M$, et al. The impact of galectin-3 inhibition on aldosterone-induced cardiac and renal injuries. JACC Heart Fail 2015;3:5967.

46. Yu L, Ruifrok WPT, Meissner M, et al. Genetic and pharmacological inhibition of galectin-3 prevents cardiac remodeling by interfering with myocardial fibrogenesis. Circ Heart Fail 2013;6:107-17.

47. Vergaro G, Prud'homme M, Fazal L, et al. Inhibition of galectin-3 pathway prevents isoproterenol-induced left ventricular dysfunction and fibrosis in mice. Hypertension 2016;67:606-12.

48. Hromádka M, Seidlerová J, Suchý D, et al. Myocardial fibrosis detected by magnetic resonance in systemic sclerosis patients - relationship with biochemical and echocardiography parameters. Int J Cardiol 2017;249:448-53.

49. Prud'homme M, Coutrot M, Michel T, et al. Acute kidney injury induces remote cardiac damage and dysfunction through the galectin-3 pathway. JACC Basic Trans Sci 2019;4:717-32.

50. Ghorbani A, Bhambhani V, Christenson $\mathrm{RH}$, et al. Longitudinal change in galectin-3 and incident cardiovascular out comes. J Am Coll Cardiol 2018;72:3246-54. 51. Christov M, Waikar SS, Pereira RC, et al. Plasma FGF23 levels increase rapidly after acute kidney injury. Kidney Int 2013; 84:776-85.

52. Christov M, Neyra JA, Gupta S, Leaf DE. Fibroblast growth factor 23 and klotho in AKI. Semin Nephrol 2019;39:57-75.

53. Dépret F, Peacock WF, Liu KD, Rafique Z, Rossignol P, Legrand M. Management of hyperkalemia in the acutely ill patient. Ann Intensive Care 2019;9:32.

54. Kohmoto O, Spitzer KW, Movsesian MA, Barry WH. Effects of intracellular acidosis on [Ca2+]i transients, transsarcolemmal Ca2+ fluxes, and contraction in ventricular myocytes. Circ Res 1990;66: 622-32.

55. Forfia PR, Watkins SP, Rame JE, Stew- art KJ, Shapiro EP. Relationship between B-type natriuretic peptides and pulmonary capillary wedge pressure in the intensive care unit. J Am Coll Cardiol 2005; 45:1667-71.

56. Palmer SC, Yandle TG, Nicholls MG, Frampton CM, Richards AM. Regional clearance of amino-terminal pro-brain natriuretic peptide from human plasma. Eur J Heart Fail 2009;11:832-9.

57. Schou M, Dalsgaard MK, Clemmesen $\mathrm{O}$, et al. Kidneys extract BNP and NTproBNP in healthy young men. J Appl Physiol (1985) 2005;99:1676-80.

58. Donadio C. Effect of glomerular filtration rate impairment on diagnostic performance of neutrophil gelatinase-associated lipocalin and B-type natriuretic peptide as markers of acute cardiac and renal failure in chronic kidney disease patients. Crit Care 2014;18:R39.

59. Niizuma S, Iwanaga $Y$, Washio $T$, et al. Clinical significance of increased cardiac troponin $\mathrm{T}$ in patients with chronic hemodialysis and cardiovascular disease: comparison to B-type natriuretic peptide and A-type natriuretic peptide increase. Kidney Blood Press Res 2019;44:1050-62.

60. Yang L, Xing G, Wang L, et al. Acute kidney injury in China: a cross-sectional survey. Lancet 2015;386:1465-71.

61. Kellum JA, Bihorac A. Artificial intelligence to predict AKI: is it a breakthrough? Nat Rev Nephrol 2019;15:663-4. 62. Ronco C, Bellomo R, Kellum JA. Acute kidney injury. Lancet 2019;394:1949-64.

63. Hollinger A, Wittebole X, François B, et al. Proenkephalin A 119-159 (Penkid) is an early biomarker of septic acute kidney injury: the Kidney in Sepsis and Septic Shock (Kid-SSS) Study. Kidney Int Rep 2018;3:1424-33.

64. Meersch M, Schmidt C, Hoffmeier A, et al. Prevention of cardiac surgery-associated AKI by implementing the KDIGO guidelines in high risk patients identified by biomarkers: the PrevAKI randomized controlled trial. Intensive Care Med 2017; 43:1551-61.

65. Legrand M, Hollinger A, VieillardBaron A, et al. One-year prognosis of kidney injury at discharge from the ICU: a multicenter observational study. Crit Care Med 2019;47(12):e953-e961.

66. Schetz M, Legrand M. A nephrologist should be consulted in all cases of acute kidney injury in the ICU: we are not sure. Intensive Care Med 2017;43:880-2.

67. Prowle JR, Kirwan CJ, Bellomo R. Fluid management for the prevention and attenuation of acute kidney injury. Nat Rev Nephrol 2014;10:37-47.

68. Faubel S, Edelstein CL. Mechanisms and mediators of lung injury after acute kidney injury. Nat Rev Nephrol 2016;12: 48-60.

69. Faubel S, Shah PB. Immediate consequences of acute kidney injury: the impact of traditional and nontraditional compli- cations on mortality in acute kidney injury. Adv Chronic Kidney Dis 2016;23:179-85.

70. Vieira JM Jr, Castro I, Curvello-Neto A, et al. Effect of acute kidney injury on weaning from mechanical ventilation in critically ill patients. Crit Care Med 2007; 35:184-91.

71. Mekontso Dessap A, Roche-Campo F, Kouatchet A, et al. Natriuretic peptidedriven fluid management during ventilator weaning: a randomized controlled trial. Am J Respir Crit Care Med 2012;186: 1256-63.

72. Barbar SD, Clere-Jehl R, Bourredjem $\mathrm{A}$, et al. Timing of renal-replacement therapy in patients with acute kidney injury and sepsis. N Engl J Med 2018;379:143142.

73. Gaudry S, Hajage D, Schortgen F, et al. Initiation strategies for renal-replacement therapy in the intensive care unit. $\mathrm{N}$ Engl J Med 2016;375:122-33.

74. Silver SA, Harel Z, McArthur E, et al. Causes of death after a hospitalization with AKI. J Am Soc Nephrol 2018;29:100110.

75. Marants R, Qirjazi E, Grant CJ, Lee TY, McIntyre CW. Renal perfusion during hemodialysis: intradialytic blood flow decline and effects of dialysate cooling. J Am Soc Nephrol 2019;30:1086-95.

76. Douvris A, Malhi G, Hiremath S, et al. Interventions to prevent hemodynamic instability during renal replacement therapy in critically ill patients: a systematic review. Crit Care 2018;22:41.

77. Legrand M, Prowle JR, Forni LG. The artificial kidney induces AKI? Not if we apply "kidney-protective" renal replacement therapy. Intensive Care Med 2020; 46:510-2.

78. Gayat E, Hollinger A, Cariou A, et al. Impact of angiotensin-converting enzyme inhibitors or receptor blockers on postICU discharge outcome in patients with acute kidney injury. Intensive Care Med 2018;44:598-605.

79. Brar S, Ye F, James MT, Hemmelgarn B, Klarenbach S, Pannu N. Association of angiotensin-converting enzyme inhibitor or angiotensin receptor blocker use with outcomes after acute kidney injury. JAMA Intern Med 2018;178:1681-90.

80. Legrand $M$, Futier E, Leone $M$, et al. Impact of renin-angiotensin system inhibitors continuation versus discontinuation on outcome after major surgery: protocol of a multicenter randomized, controlled trial (STOP-or-NOT trial). Trials 2019;20:160.

81. Harel Z, Wald R, Bargman JM, et al. Nephrologist follow-up improves all-cause mortality of severe acute kidney injury survivors. Kidney Int 2013;83:901-8.

82. Siew ED, Peterson JF, Eden SK, et al. Outpatient nephrology referral rates after acute kidney injury. J Am Soc Nephrol 2012;23:305-12.

Copyright @ 2020 Massachusetts Medical Society. 